\title{
PERBEDAAN HASIL BELAJAR MATEMATIKA SISWA YANG DIAJAR DENGAN MODEL PEMBELAJARAN KOOPERATIF TIPE MAKE A MATCH DAN MODEL PEMBELAJARAN AKTIF TIPE INDEX CARD MATCH BERBANTUAN SOFTWARE GEOGEBRA
}

\author{
Hikmatul Fadhilah Sianipar ${ }^{1}$, Asmin ${ }^{2}$ \\ ${ }^{1,2)}$ FMIPA, UNIMED Medan, Sumatera Utara, Indonesia \\ E-mail: fadhilah525@gmail.com
}

\begin{abstract}
ABSTRAK
Penelitian ini bertujuan untuk mengetahui apakah terdapat perbedaan hasil belajar antara siswa kelas VII SMP Negeri 5 Binjai yang diajar menggunakan model pembelajaran kooperatif tipe Make a Match dengan menggunakan model pembelajaran aktif tipe Index Card Match. Populasi dalam penelitian ini adalah seluruh siswa kelas VII SMP Negeri 5 Binjai yang terdiri dari 7 kelas dan sampel dalam penelitian ini adalah siswa kelas VII-2 dan kelas VII-4 sebanyak 52 siswa. Kelas VII-2 diajar menggunakan model kooperatif tipe Make a Match dan kelas VII-4 diajar menggunakan model aktif tipe Index Card Match. Jenis penelitian ini adalah eksperimen semu. Data yang digunakan adalah tes PAM yang diambil dari 15 butir soal UN Sekolah Dasar dan postest berbentuk uraian sebanyak 5 soal untuk melihat hasil belajar matematika siswa. Sebelum pengujian hipotesis terlebih dahulu diuji normalitas tes dengan menggunakan uji Chi Square dan homogenitas tes menggunakan uji F. Dari pengujian yang dilakukan diperoleh bahwa hasil tes PAM kedua sampel berasal dari populasi yang berdistribusi normal dan homogen, dengan demikian penulis bisa memberikan perlakuan kepada kedua sampel. Dari hasil analisis data diperoleh nilai rata-rata hasil belajar matematika siswa yang diberi model pembelajaran kooperatif tipe Make a Match adalah 75,68 dengan simpangan baku 4,90 dan rata-rata hasil belajar matematika siswa yang diberi model pembelajaran aktif tipe Index Card Match adalah 70,53 dengan simpangan baku 5,85. Untuk uji hipotesis digunakan uji t, dari hasil perhitungan diperoleh $t_{\text {hitung }}=3,43875$ dan $t_{\text {tabel }}=2,01$. Ternyata $t_{\text {hitung }}>t_{\text {tabel }}$, sehingga Ho ditolak dan Ha diterima sehingga diperoleh kesimpulan bahwa terdapat perbedaan antara hasil belajar matematika siswa yang diajar dengan model pembelajaran kooperatif tipe Make a Match dan model pembelajaran aktif tipe Index Card Match berbantuan Software Geogebra.
\end{abstract}

Kata kunci: hasil belajar, make a match, index card match, geogebra

\begin{abstract}
This study aims to determine whether there are differences in learning outcomes between students of class VII SMP Negeri 5 Binjai who was taught using cooperative learning model type Make a Match by using the model of active learning type Index Card Match. The population in this research is all students of class VII of SMP Negeri 5 Binjai which consists of 7 classes and the sample in this research are students of class VII-2 and class VII-4 as many as 52 students. Class VII-2 was taught using a Make a Match type of cooperative model and VII-4 classes were taught using an active model of Index Card Match type. This type of research is a pseudo experiment.

Hikmatul Fadhilah Sianipar, Asmin. Perbedaan Hasil Belajar Matematika Siswa yang Diajar dengan Model Pembelajaran Kooperatif Tipe Make A Match dan Model Pembelajaran Aktif Tipe Index Card Match Berbantuan Software Geogebra. Inspiratif, Vol. 3. No. 1 April 2017.
\end{abstract}


The data used is the PAM test taken from 15 items of UN Primary School and postest in the form of a description of 5 questions to see the students' mathematics learning outcomes. Before testing the hypothesis first tested the normality of the test by using Chi Square test and the homogeneity of the test using the F test. From the test it was obtained that the results of the PAM test of both samples came from a population of normal and homogeneous distribution, thus the authors can give treatment to both samples. From the results of data analysis obtained the average value of mathematics learning outcomes of students who are given a model of cooperative learning type Make a Match is 75.68 with standard deviation 4.90 and the average of mathematics learning outcomes of students who are given an active model of learning type Index Card Match is 70.53 with standard deviation 5.85. To test the hypothesis used t test, from the calculation results obtained tcount $=3.43875$ and ttabel $=2.01$. Apparently thitung $>$ ttabel, so Ho is rejected and Ha accepted so that obtained the conclusion that there is a difference between mathematics learning outcomes of students who are taught with cooperative learning model type Make a Match and active learning model type Index Card Match Software Geogebra.

Keywords: study results, make a match, index card match, geogebra

\section{Pendahuluan}

Pendidikan adalah usaha sadar dan terencana untuk mewujudkan suasana belajar dan proses pembelajaran agar siswa secara aktif mengembangkan potensi dirinya untuk memiliki kekuatan spiritualkeagamaan, pengendalian diri, kepribadian, akhlak mulia serta keterampilan yang dibutuhkan dirinya, masyarakat, bangsa dan negara (UU Nomor 20 Tahun 2003 tentang Sistem Pendidikan Nasional). Oleh karena itu, pendidikan sebagai basis dari sebuah pengetahuan bukan hanya merupakan tanggung jawab dari perseorangan ssaja, melainkan tanggung jawab bersama antara lembaga-lembaga pendidikan.

Pendidikan memberikan kemungkinan pada siswa untuk memperoleh "kesempatan", "harapan", dan pengetahuan agar dapat hidup secara lebih baik. Besarnya kesempatan dan harapan sangat bergantung pada kualitas pendidikan yang ditempuh. Pendidikan juga dapat menjadi kekuatan untuk melakukan perubahan agar sebuah kondisi menjadi lebih baik. Pendidikan yang berkualitas tentunya melibatkan siswa untuk aktif belajar dan mengarahkan terbentuknya nilai-nilai yang dibutuhkan oleh siswa dalam menempuh kehidupan (Surya, Putri dan Mukhtar, 2017)
Pendidikan

matematika mempunyai peranan bagi setiap individu untuk melatih kemampuan berfikir logis, kritis, sistematis, kreatif dan kemauan bekerjasama yang efektif. Cara berfikir seperti ini yang dapat dikembangkan melalui pendidikan matematika karena matematika memiliki struktur dengan keterkaitan yang kuat dan jelas antara yang satu dengan yang lainnya, serta memerlukan pola pikir yang bersifat deduktif dan konsisten. Hal ini sesuai dengan banyaknya pendapat yang telah disumbangkan matematika untuk kemajuan peradaban manusia.

Sekolah pada pendidikan dasar memiliki peran penting dalam penanaman konsep matematika secara formal menuju jenjang pendidikan selanjutnya yang lebih tinggi. Seiring perkembangan zaman, pembaharuan di bidang pendidikan dalam rangka peningkatan mutu terus dilakukan. Akan tetapi hasil belajar siswa pada bidang studi matematika berdasarkan UN SMP yang diadakan tidak mengalami perubahan yang berarti setiap tahunnya. Salah satunya dapat dilihat dari hasil UN SMP Negeri 5 Binjai.

\section{Tabel 1. Hasil UN SMP Negeri 5 Binjai}

\begin{tabular}{|c|c|c|c|c|}
\hline Kategori & B.Indo & B.Ing & Mat & IPA \\
\hline Rata-Rata & 63,09 & 72,24 & 46,25 & 79,87 \\
\hline Terendah & 28,0 & 24,0 & 12,5 & 15,0 \\
\hline Tertinggi & 96,0 & 96,0 & 92,5 & 95,0 \\
\hline
\end{tabular}

Hikmatul Fadhilah Sianipar, Asmin. Perbedaan Hasil Belajar Matematika Siswa Yang Diajar Dengan Model Pembelajaran Kooperatif Tipe Make A Match Dan Model Pembelajaran Aktif Tipe Index Card Match Berbantuan Software Geogebra. Inspiratif, Vol. 3. No. 1 April 2017. 
Tabel 2 Hasil UN SMP Negeri 5 Binjai

\begin{tabular}{|c|c|c|c|c|}
\hline Kategori & B.Indo & B.Ing & Mat & IPA \\
\hline $\begin{array}{c}\text { Rata- } \\
\text { Rata }\end{array}$ & 59,74 & 42,21 & 41,24 & 75,25 \\
\hline Terendah & 28,0 & 24,0 & 22,5 & 32,5 \\
\hline Tertingi & 94,0 & 94,0 & 90,0 & 97,5 \\
\hline
\end{tabular}

(Sumber: SMP Negeri 5 Binjai)

Terdapat beberapa model pembelajaran yang dapat digunakan untuk meningkatkan hasil belajar siswa salah satunya dengan model pembelajaran kooperatif tipe Make a Match. Selain itu, model pembelajaran aktif tipe Index Card Match merupakan salah satu model pembelajaran yang mampu meningkatkan keaktifan siswa dalam proses belajar. Kedua model pembelajaran tersebut dirancang agar siswa dapat berpikir, mengemukakan pendapat, memberikan pendapat, dan saling membantu dengan rekan lain. Model pembelajaran ini diharapkan dapat memberikan hasil positif dan meningkatkan hasil belajar siswa. Surya (2009) menyatakan pembelajaran kooperatif dengan berbasis masalah dapat memecahkan masalah matematika dan kehidupan seharihari.

Komputer merupakan salah satu media yang masih popular di kalangan siswa yang bisa membuat pembelajaran menarik. Erman Suherman, 5 dkk (2003: 293) mengemukakan komputer memiliki potensi yang besar untuk meningkatkan kualitas pembelajaran, khususnya dalam pembelajaran matematika. Banyak hal absatrak yang sulit dipikirkan siswa dapat dipresentasikan melalui simulasi komputer. Hal ini tentu saja akan lebih menyederhanakan jalan pikiran siswa dalam memahami matematika.

Salah satu aplikasi komputer yang dapat digunakan dalam belajar matematika adalah software GeoGebra. Software GeoGebra menjadi pilihan peneliti karena melihat karakteristik siswa-siswa SMP yang masih menyukai konsep permainan.
Software GeoGebra berfungsi sebagai media gambar yang dinamis sehingga siswa akan bermain dengan geseran titik-titik ataupun pengukuran ruas garis dan luasan. Secara umum software GeoGebra akan menyediakan pengalaman langsung kepada siswa dalam belajar. Dengan demikian, software GeoGebra mendukung kegiatan penemuan dan dapat memotivasi siswa dalam belajar.

Permasalahan yang timbul adalah adakah perbedaan pada hasil belajar siswa kelas VII SMP Negeri 5 Binjai antara pembelajaran menggunakan model pembelajaran kooperatif tipe Make a Match dengan menggunakan model pembelajaran aktif tipe Index Card Match?

\section{Metode}

Untuk menjawab permasalahan di atas telah dilakukan penelitian kuasi eksperimen. Populasi dalam penelitian ini adalah seluruh kelas VII SMP Negeri 5 Binjai. Cara pengambilan sampel yaitu dengan random sampling, dengan kelas VII-2 sebagai kelas eksperimen 1 dan kelas VII-4 sebagai kelas eksperimen 2. Pada kelas eksperimen I diberi perlakuan yaitu pengajaran materi jajargenjang dan belah ketupat menggunakan model pembelajaran kooperatif tipe Make a Match, sedangkan pada kelas eksperimen II diberi perlakuan yaitu pengajaran materi jajargenjang dan belah ketupat menggunakan model pembelajaran aktif tipe Index Card Match. Untuk mengetahui hasil belajar matematika yang diperoleh dari penerapan perlakuan tersebut, maka siswa diberikan tes. Adapun bentuk desain yang digunakan adalah Posttest Only Control Group Design. Berikut ini rancangan penelitian yang akan dilakukan (menurut Arikunto, 2013:212), yaitu:

Tabel 3. Desain Penelitian

\begin{tabular}{|c|c|c|}
\hline Kelas & Perlakuan & Tes Akhir \\
\hline Eksperimen I & $\mathrm{X}_{1}$ & $\mathrm{O}$ \\
\hline Eksperimen II & $\mathrm{X}_{2}$ & $\mathrm{O}$ \\
\hline
\end{tabular}

Hikmatul Fadhilah Sianipar, Asmin. Perbedaan Hasil Belajar Matematika Siswa Yang Diajar Dengan Model Pembelajaran Kooperatif Tipe Make A Match Dan Model Pembelajaran Aktif Tipe Index Card Match Berbantuan Software Geogebra. Inspiratif, Vol. 3. No. 1 April 2017. 
$\mathrm{O}:$ Postes

$\mathrm{X}_{1}$ : Pembelajaran menggunakan model kooperatif tipe Make A Match

$\mathrm{X}_{2}$ : Pembelajaran menggunakan model pembelajaran tipe Index Card Match

Instrument yang digunakan untuk menentukan hasil belajar matematika siswa adalah tes. Bentuk tes yang akan digunakan adalah essay test yang disusun berdasarkan indikator hasil belajar matematika siswa. Dalam penelitian ini, tes yang digunakan adalah tes akhir (posttest) yaitu tes untuk mengetahui hasil belajar matematika siswa setelah dilakukan pembelajaran dengan materi jajargenjang dan belah ketupat.

Prosedur penelitian yang dilakukan terdiri dari (1) tahap persiapan; (2) tahap pelaksanaan; (3) tahap penyelesaian. Adapun langkah yang sudah dipersiapakan sampai pada saat pelaksanaan penelitian yaitu; menetapkan sekolah dan observasi, mengumpulkan data, menetapkan jadwal, mengurus surat izin, menentukan kelas sampel, mempersiapkan perangkat pembelajaran, soal tes akhir berupa soal essay yang sebelumnya sudah divalidasi.

\section{Hasil dan Pembahasan}

Data tentang hasil tes hasil belajar matematika yang dilaksanakan pada kelas VII-2 dan VII-4. Hasil perhitungan berupa hasil analisis data tes akhir yang dapat dilihat pada Tabel 4 berikut:

Tabel 4. Rekapitulasi Hasil Posttest Kelas Eksperimen I dan II

\begin{tabular}{|l|c|c|}
\hline \multicolumn{1}{|c|}{ Statistik } & Kelas Eksp 1 & Kelas Eksp 2 \\
\hline $\mathrm{N}$ & 26 & 26 \\
\hline Jumlah Nilai & 1967,58 & 1833,73 \\
\hline Rata-rata & 75,68 & 70,53 \\
\hline $\begin{array}{l}\text { Simpangan } \\
\text { Baku }\end{array}$ & 4,90 & 5,85 \\
\hline Varians & 24,04 & 34,23 \\
\hline Maksimum & 84,61 & 80 \\
\hline Minimum & 69,23 & 63,07 \\
\hline
\end{tabular}

Berdasarkan data pada tabel di atas, diketahui bahwa skor rata-rata nilai tes hasil belajar kelas eksperimen 1 adalah 75,68 dan untuk kelas eksperimen 2 adalah 70,53. Nilai tertinggi di kelas eksperimen 1 yaitu 84,61 dan pada kelas eksperimen 2 adalah 80. Sedangkan nilai terendah untuk kelas eksperimen 1 adalah 69,23 dan kelas eksperimen 2 adalah 63,07. Simpangan baku untuk kelas eksperimen 1 adalah 4,90 dan kelas eksperimen 2 adalah 5,85. Data ini selanjutnya akan digunakan sebagai landasan untuk melakukan uji statistik.

\section{A. Uji Normalitas Data}

Uji normalitas dilakukan untuk mengetahui apakah sampel data berasal dari populasi berdistribusi normal atau tidak. Secara umum, sampel berdistribusi normal jika dipenuhi $\chi_{\text {hitung }}^{2}<\chi_{\text {tabel }}^{2}$ pada taraf $\alpha=0,05$.

Tabel 5. Hasil Analisis Normalitas Posttest

\begin{tabular}{|c|c|c|c|c|c|}
\hline \multicolumn{2}{|c|}{ Eksperimen I } & \multirow{2}{*}{ Keterangan } & \multicolumn{2}{|l|}{ Eksperimen II } & \multirow{2}{*}{ Keterangan } \\
\cline { 4 - 5 } & & $\chi_{\text {hitung }}^{2}$ & $\chi_{\text {tabel }}^{2}$ & \\
\hline$\chi_{\text {hitung }}^{2}$ & $\chi_{\text {tabel }}^{2}$ & & 10,11 & 11,1 & Normal \\
\hline 10,698 & 11,1 & Normal & & & Nor \\
\end{tabular}

Dari Tabel 5. terlihat bahwa $\chi_{\text {hitung }}^{2}<$ $\chi_{\text {tabel }}^{2}$ pada taraf nyata $\alpha=0,05$. Dengan demikian dapat disimpulkan bahwa distribusi posttest pada kedua kelas adalah normal.

\section{B. Uji Homogenitas Data}

Pengujian homogenitas data dilakukan dengan menggunakan uji $\mathrm{F}$ pada data posttest dengan rumus sebagai berikut

$$
F_{\text {hitung }}=\frac{\text { variansterbesar }}{\text { variansterkecil }}
$$

Tabel 6. Hasil Analisis Homogenitas Data Penelitian

\begin{tabular}{|c|c|c|l|}
\hline \multicolumn{2}{|c|}{ Varians } & \multirow{2}{*}{ F $_{\text {hitung }}$} & \multicolumn{1}{|c|}{$\mathbf{F}_{\text {tabel }}$} \\
\cline { 1 - 2 } Eks 1 & Eks 2 & 0,7023 & 1,96 \\
24,04 & 34,23 & 9 & 1,96 \\
\hline
\end{tabular}

Hikmatul Fadhilah Sianipar, Asmin. Perbedaan Hasil Belajar Matematika Siswa Yang Diajar Dengan Model Pembelajaran Kooperatif Tipe Make A Match Dan Model Pembelajaran Aktif Tipe Index Card Match Berbantuan Software Geogebra. Inspiratif, Vol. 3. No. 1 April 2017. 
Pada tabel diatas terlihat bahwa pada post-tes, harga $F_{\text {hitung }}<\mathrm{F}_{\text {tabel }}$ artinya setiap sampel mempunyai varians yang sama atau tidak berbeda.

Berdasarkan tabel 3.2. dan tabel 3.3. dapat disimpulkan bahwa telah memenuhi syarat untuk dilakukan uji beda rata-rata dengan uji-t.

\section{Uji Hipotesis Data}

Hipotesis yang diuji untuk Posttest adalah :

$$
\begin{array}{ll}
H_{o}: & \mu_{1} \leq \mu_{2} \\
H_{a}: & \mu_{1}>\mu_{2}
\end{array}
$$

Pengujian hipotesis ini dilakukan dengan uji-t satu arah yaitu pihak kanan, dengan kriteria yaitu terima $\mathrm{H}_{0}$ jika $\mathrm{t}_{\text {hitung }}<\mathrm{t}_{\text {tabel }}$. Dimana didapat dari daftar distribusi $\mathrm{t}$ dengan $\mathrm{dk}=\left(n_{1}+n_{2}-2\right)$ pada taraf signifikan $\alpha=0,05$, untuk harga t lainnya $\mathrm{H}_{0}$ ditolak.

Tabel 7. Ringkasan Perhitungan Uji Hipotesis

\begin{tabular}{|c|c|c|c|}
\hline \multicolumn{2}{|c|}{ Rata-rata } & \multirow{2}{*}{$\mathfrak{t}_{\text {hitung }}$} & \multirow{2}{*}{$\mathrm{t}_{\text {tabel }}$} \\
\cline { 1 - 2 } Eks 1 & Eks 2 & & \\
\hline 75,68 & 70,53 & 3,43875 & 2,01 \\
\hline
\end{tabular}

Dalam hal ini berlaku ketentuan bahwa bila thitung lebih besar atau samadengan ttabel, maka Ha diterima. Ternyata thitung lebih besar daripada tabel $(3,43875>2,01)$. Dengan demikian, Ha diterima dan Ho ditolak. Berdasarkan data hasil belajar matematika mahasiswa pada pokok bahasan jajargenjang dan belah ketupat, menunjukkan bahwa mean hasil belajar kelas yang menggunakan model pembelajaran kooperatif tipe Make A Match lebih tinggi dari mean hasil belajar kelas yang menggunakan pembelajaran aktif tipe Index Card Match. Dari perhitungan tes "t" diperoleh th lebih besar dari tt pada taraf signifikan 5\%. Hal ini menunjukkan bahwa penerapan model pembelajaran Make A Match dan Index Card Match dalam pembelajaran matematika menyebabkan adanya perbedaan hasil belajar matematika siswa. Di mana hasil belajar kelas eksperimen 1 lebih tinggi dari kelas eksperimen 2. Perbedaan mean kedua variabel menunjukkan bahwa penggunaan model pembeajaran kooperatif tipe Make A Match lebih baik dari pada pembelajaran aktif tipe Index Card Match. Dengan demikian, hasil analis ini mendukung rumusan masalah yaitu rata-rata hasil tes hasil belajar siswa yang memperoleh model pembelajaran matematika dengan model Make A Match lebih tinggi daripada model pembelajaran Index Card Match.

Untuk memperkuat hasil penelitian ini, peneliti membandingkan hasil penelitian yang diperoleh dengan hasil penelitian terdahulu yang relevan dengan penelitian ini. Berikut disajikan hasil penelitian terdahulu yang relevan dengan penelitian ini.

Penelitian yang relevan terhadap penelitian yang dilakukan peneliti adalah hasil penelitian yang dilakukan oleh Sapawardi (2015), "Pengaruh Cooperative Learning tipe Make A Match Terhadap Motivasi Dan Hasil Belajar Matematika Siswa". Dari penelitian yang dilakukan, disimpulkan bahwa terdapat pengaruh cooperative learning tipe Make A Match terhadap hasil belajar matematika siswa.

Perbedaan hasil belajar siswa diakibatkan oleh beberapa faktor. Salah satunya adalah langkah-langkah pembelajaran yang berbeda. Model pembelajaran kooperatif tipe Make a Match dan model pembelajaran aktif tipe Index Card Match sama-sama menuntut siswa untuk menemukan pasangan kartu yang cocok, namun dalam pelaksanaan pembelajarannya memiliki perbedaan. Model pembelajaran Make a Match membagi siswa mejadi 3 kelompok besar dalam kelas, yang salah satu kelompok berperan sebagai kelompok pembanding. Setelah menjadi kelompok pembanding, kelompok pembanding juga akan menjadi kelompok yang mendapatkan kartu sehingga nantinya juga akan bermain mencari kartu pasangan. Berbeda dengan model 
pembelajaran aktif tipe Index Card Match yang membagi siswa dalam 2 kelompok besar dan hanya sebatas mencocokkan kartu saja dan tidak melewati tahap berdiskusi mengenasi hasil presenasi pasangan kartu seperti halnya kelompok pembanding yang berada di model pembelajaran kooperatif tipe Make a Match. Hal tersebut menjadikan hasil belajar siswa di kelas menggunakan model pembelajaran kooperatif tipe Make a Match dengan kelas menggunakan model pembelajaran aktif tipe Index Card Match berbeda.

Model kooperatif tipe make a match menjadi lebih efektif digunakan karena model kooperatif tipe make a match menerapkan teori Vygotsky dan Behaviorisme yang menyatakan bahwa belajar merupakan perubahan tingkah laku, seseorang dianggap belajar sesuatu bila ada menunjukkan perubahan tingkah laku. Hal ini dapat dikembangkan dalam bentuk kerjasama antara peserta didik dengan peserta didik lainnya yang lebih mampu di bawah bimbingan orang dewasa dan guru. Sehingga kualitas berfikit dan aktifitas peserta didik dapat lebih dibina.

Meskipun demikian, baik Make A Match maupun Pembelajaran aktif tipe Index Card Match ternyata sama-sama dapat meningkatkan hasil belajar siswa di kedua kelas tersebut pada materi jajargenjang dan belah ketupat. Hal ini dapat terlihat dari nilai yang ada pada kedua kelas dapat memenuhi kriteria ketuntasan minimal (KKM) di sekolah tersebut. Dimana KKM untuk mata pelajaran matematika di sekolah itu adalah 7. Dari tabel hasil belajar dapat dilihat rata-rata nilai siswa pada kelas eksperimen 1 mencapai 75,68 dan pada kelas eksperimen 2 mencapai 70,53. Selain itu perlakuan yang diberikan di kedua kelas, baik dengan model pembelajaran kooperatif tipe Make A Match maupun Pembelajaran aktif tipe Index Card Match membuat siswa menjadi lebih aktif selama kegiatan pembelajaran. Seperti yang diungkapkan Azizah (2015) bahwa salah satu keunggulan pembelajaran Make a Match adalah mendidik siswa untuk berlatih bersosialisasi dengan orang lain dan hasil belajar siswa lebih baik.

Dari kedua model pembelajaran yang diterapkan dapat disimpulkan ada beberapa kelemahan-kelemahan yang ditemukan dalam penelitian ini yaitu : adanya kemungkinan siswa kurang bersungguhsungguh dalam menyelesaikan soal yang diberikan oleh peneliti, lingkungan kelas yang tidak mendukung seperti adanya beberapa siswa yang sering membuat keributan karena sulit memahami pelajaran sehingga membuat kondisi kelas menjadi tidak kondusif, dan diperlukan waktu yang cukup banyak untuk melakukan kegiatan pembelajaran sedangkan alokasi waktu yang tersedia dalam kurikulum sangat terbatas.

Dengan demikian peneliti akan memperbaiki kelemahan peneliti dalam penelitian selanjutnya sehingga dapat memperoleh hasil yang lebih baik lagi.

\section{Kesimpulan}

Berdasarkan hasil penelitian, dapat diambil kesimpulan sebagai berikut: Hasil belajar matematika siswa menggunakan model pembelajaran kooperatif tipe Make A Match lebih tinggi daripada hasil belajar matematika siswa menggunakan model pembelajaran aktif tipe Index Card Match di SMP Negeri 5 Binjai Tahun Ajaran 2016/2017. Dilihat dari rata-rata skor pada kelas eksperimen I sebesar 75,68 sementara skor rata-rata pada kelas eksperimen II sebesar 70,53. Pengujian hipotesis dilakukan dengan menggunakan uji-t. Setelah dilakukan pengujian data ternyata diperoleh $t_{\text {hitung }}>t_{\text {tabel }}$ yaitu 3,43875 $>2,01$, maka $\mathrm{H}_{0}$ ditolak dan $\mathrm{H}_{\mathrm{a}}$ diterima. Dengan demikian dapat disimpulkan bahwa hasil belajar matematika siswa menggunakan model pembelajaran kooperatif tipe Make A Match lebih tinggi dari hasil belajar matematika siswa menggunakan model pembelajaran aktif tipe Index Card Match. 


\section{DAFTAR PUSTAKA}

Arikunto, S, (2013), Manajemen Penelitian, Rineka Cipta, Jakarta.

Hudojo, H., (2005), Pengembangan Kurikulum dan Pembelajaran Matematika, UM Press, Malang.

Sapawardi, L. (2015). Pengaruh Cooperative Learning tipe Make A Match Terhadap Motivasi Dan Hasil Belajar Matematika Siswa. Jurnal Pendidikan Matematika. Vol. 8. No. 1. ISSN 2085-5893.

Siregar, A. Peningkatan Hasil Belajar Dan Aktivitas Matematika Siswa Melalui Penerapan Model Pembelajaran Kooperatif Tipe Make A Match Pada Materi Himpunan Di Kelas VII SMP Swasta Gajah Mada Medan T.A 2014/201. Medan: FMIPA UNIMED.

Slavin, R.E, (2005), Cooperative Learning, Teori Riset dan Praktik, Nusa Media, Bandung.

Suherman, E., \& Winaraputra, Udin S. (1999), Strategi Belajar Mengajar Matematika PAMA 32113 SKS/Modul. Jakarta: UT.

Surya, E. (2009). Pembelajaran Kooperatif dengan Pendekatan Berbasis Masalah Dalam Pemecahan Masalah Matematika. Jurnal Pendidikan Matematika dan Sains, 4 (1), 14-17.

Surya, E. Putri, F.A. and Mukhtar. 2017. Improving Mahematical Problem Solving Ability and Self-Confidence of High School Students Through Contextual Learning Model. Indonesian Mathematical Society Journal on Mathematics Education, 8(1), 85-94.

Susanto, A., (2013), Teori Belajar dan Pembelajaran di Sekolah Dasar, Prenada Media Group, Jakarta.
Trianto, (2010), Mendesain Model Pembelajaran Inovatif-Progresif : Konsep, Landasan, dan Implementasinya Pada Kurikulum Tingkat Satuan Pendidikan (KTSP), Kencana Prenada Media Group, Jakarta. 